Finisterra, XXXVI, 72, 2001, pp. 75-81

\title{
ACERCA DE «PAISAGEM»: Apontamentos para um debate
}

ILÍDIO DO AMARAL 1

\begin{abstract}
"Car le paysage, support de la vie, concerne chaque habitant qui en est l'héritier, l'auteur, l'utilisateur et, bien sûr, l'observateur admiratif ou consterné» (Jean-Robert PITTE, Histoire du paysage français, 1983, I, p. 24)
\end{abstract}

\section{NOTAS PREAMBULARES}

Não se trata de um artigo sobre "paisagem» porque, para isso, me faltam engenho e arte, mas apenas um conjunto de apontamentos, nem sempre bem concatenados, para um debate.

Do latim pagus, significando o campo ou território cultivado, proveio o francês pays e daqui paysan e paysage. Em italiano, com a mesma origem, resultou paesaggio e em espanhol paisaje. Nas línguas germânicas, em inglês e em alemão, de uma raiz comum, land, com significado idêntico ao de pagus, e também de região e país, se formaram landscape e Landschaft. Em holandês a palavra é landschaf e em sueco landskap. Interessante notar que a forma inglesa antiga, da Idade Média, era landscipe, usada para um território pertencente a um senhor ou habitado por um grupo particular de gente.

A utilização de landscape data de finais do século XVI ou princípios do XVII, quando a influência de pintores paisagistas holandeses encorajou o renascimento e redefinição de "paisagem» para referir as representações de cenas, sobretudo as rurais, e depois panoramas, em geral ou um aspecto particular (Preston James, «The terminology of regional description», Annals, Association of American Geographers, 1934, 24, pp. 78-86). Sem artigo, landscape significa o mundo visível, tudo o que pode ser visto da superfície terrestre por alguém que esteja, ele próprio, nessa superfície; e com artigo, a landscape, já se refere a um pedaço da superfície terrestre que pode ser visto num relance de olhos.

1 Geógrafo, Professor Catedrático Jubilado da Faculdade de Letras da Universidade de Lisboa, um dos fundadores de Finisterra, seu colaborador e também do Centro de Estudos Geográficos. Director do Centro de Geografia do Instituto de Investigação Científica Tropical. 
Em português «paisagem» não parece ter sido aquisição directa através de pagus, mas a importação e adaptação do francês paysage em meados do século XVII.

Em linguagem corrente «paisagem» tem o significado de extensão de território abarcada pelo campo de visão de um observador - «nearly everything we see when we go outdoors» (Peirce Lewis, ed., Visual blight, Association American Geographers, 1973, Resource Paper 23) -, podendo ser diferentes as formas como este exprime o visualizado. Por isso a utilização da palavra em campos tão diversos como das ciências naturais, das humanidades e ciências sociais, das artes. Também se pode acrescentar a "paisagem» interior, de um estado de espírito, ou emocional. O neurologista António Damásio usa a expressão «paisagem corporal» como resultado de dois mecanismos ou sinais de modificação do estado corporal, sendo representada, subsequentemente, nas estruturas somatossensoriais do sistema nervoso central (A. Damásio, O Sentimento de Si. O Corpo, a Emoção e a Neurobiologia da Consciência, Lisboa, 2000, p. 321).

\section{II. À PROCURA DE UMA DEFINIÇÃO GEOGRÁFICA}

Há quem defenda que a Geografia, tendo como objectivo o estudo das relações entre o homem e a natureza, assuma a responsabilidade pelo da "paisagem», um domínio ainda mal estruturado, que não é reclamado por qualquer outra disciplina. Na formulação da "paisagem», ou em qualquer outro tipo de análise, a Geografia compromete duas variáveis fundamentais: o espaço e o tempo. Daí que a maioria das definições a relacionem com organização ou arranjo do espaço, dando grande atenção à análise estruturada das sua transformações. Há quem considere que, virtualmente, todas as "paisagens» foram afectadas, de algum modo, pela acção ou percepção humana desde o Neolítico; logo, a expressão "paisagem cultural» não deverá ser utilizada para significar um determinado tipo de paisagem, mas sim uma maneira de ver a "paisagem» que releva a interacção entre os seres humanos e a natureza ao longo dos tempos (Institute for Cultural Landscapes Studies, Harvard University). Deste modo, até que ponto valerá à pena insistir na antinomia "paisagem natural»e «paisagem cultural»?

Sendo o registo da "paisagem» um processo cerebral, uma percepção que pode ser transmitida pela fala, pela escrita, pela pintura ou pela música, cada um dos agentes é produtor de espaços e também seu utilizador. A representação é sempre polissémica e a figura geográfica, organizada por geogramas, destinada a convencer, é, por natureza, funcional e deve ser visivelmente persuasiva (Augustin Berque, "Géogrammes pour une ontologie de faits géographiques», L'Espace Géographique, 1999, 4, p. 321).

Tem sido questionado o relevo dado ao tema "paisagem» e há várias definições para "geografia da paisagem». Segundo Paul Claval, reconhecendo a sua inquestionável popularidade entre os geógrafos contemporâneos, afirma que 
ele «oferece a possibilidade de abordar num mesmo movimento todas as questões candentes do futuro da geografia: as que giram à volta do peso do meio e dos constrangimentos ecológicos na organização do espaço, as que nascem do funcionamento de instituições sociais e de tensões e conflitos que elas alimentam, e as que permitem perceber em que é que o homem difere de um ponto a outro - e o exprime por uma organização do espaço diferente» (P. Claval, Géographie humaine et économique contemporaine, Paris, 1984, pp. 341-342). Ainda segundo o mesmo autor, durante algum tempo pareceram confundir-se «análise de paisagens e estudos regionais», quando «se pensava poder descrever a terra como um mosaico de áreas homogéneas». Contudo, dissipou-se tal «esperança com a descoberta da complexidade das paisagens e a tomada em conta, na organização do espaço, das relações, dos fluxos e dos aspectos funcionais. Mas os dois domínios têm em comum oferecer aos geógrafos contemporâneos a oportunidade de recorrer a todos os aspectos da disciplina». Assim se verá «melhor como se combinam os modelos do meio, os modelos do social e os modelos do homem» (P. Claval, Idem, p. 354).

Não menos interessante é a definição de Jean-Robert Pitte, antecedendo de um ano a de Paul Claval: «a paisagem é a expressão observável à superfície da terra, pelos sentidos, da combinação entre a natureza, as técnicas e a cultura dos homens. Ela é, essencialmente, mudável e não pode ser apreendida senão na sua dinâmica, isto é, no quadro da história que lhe restitui a sua quarta dimensão. Se a ecologia lembra que a natureza tem as suas leis fundamentais e que é oneroso transgredi-las, a história ensina que o homem tem as suas razões que a natureza ignora. A paisagem é acto de liberdade; é uma poesia caligrafada na folha branca do climax» (Jean-Robert Pitte, Histoire du paysage français. I. Le Sacré: de la Préhistoire au XVe siècle, Paris, 1983, p. 24).

\section{UTOPIA E REALIDADE}

Vejamos alguns exemplos em que estão presentes dois aspectos fundamentais que se relacionam não só com as noções de tempo e espaço, mas também com a de tempo-espaço: a utopia e a realidade.

É inegável que Luís de Camões, em Os Lusíadas (1572), associou ao seu saber de poeta épico a compreensão geográfica das coisas da superfície terrestre. Sirvam de exemplo, entre muitos, o rigor da descrição de uma tromba marinha vista antes da passagem do cabo de Boa Esperança (Canto V, estr. 18-19) e a descrição sumária da Europa (Canto III, estr. 6-20). Mas o que aqui nos interessa é a descrição da Ilha dos Amores, "suave e deleitosa» (Canto X, estr. 51-63), que o poeta sugere algures na zona tropical: «Três formosos outeiros se mostravam, [...] Que de gracioso esmalte se adornavam, [...] Claras fontes e límpidas manavam/ Do cume, que a verdura tem viçosa; / Por entre pedras alvas se deriva/ A sonora linfa fugitiva. / Num vale ameno, que os outeiros fende, / Vinham as claras águas ajuntar-se, / Onde uma mesa fazem, que se 
estende, / Tão bela quanto pode imaginar-se [...] Mil árvores estão ao céu subindo, / Com pomos odoríferos e belos», etc. Perante estas palavras, ainda que impregnadas de bucolismo poético, o leitor é sugestionado a compor, mentalmente, uma imagem ou "paisagem» da ilha. Só que esta porção de espaço insular foi, pura e simplesmente, uma invenção poética de Camões, num daqueles momentos em que substituiu a apreensão da realidade geográfica pela tradição mitológica. Camões pretendeu fazer ver uma paisagem idílica servindo de quadro a aventuras arcadianas, no estilo das representações paisagísticas de Giorgione, discípulo dos Bellini, de Ticiano e de outros ilustres pintores quinhentistas. O Conde de Ficalho, em A Flora dos Lusíadas, 1880, pode demonstrar que o "gracioso esmalte», entenda-se verdura, e as "mil árvores», as frutas, a maior parte nada tinha de tropical; as espécies arbóreas mencionadas por Camões (álamos, loureiros, pinheiros, ciprestes, etc.), bem como as fruteiras (cerejeiras, amoreiras, pessegueiros, romãzeiras, videiras) eram da flora mediterrânea, talvez porque tivesse considerado ser esse o cenário mais adequado para as deusas e ninfas que iam receber os cansados marinheiros da frota de Vasco da Gama.

Outro exemplo é retirado do livro segundo de The New Island of Utopia, de Thomas More ( $1 .^{a}$ edição em latim, 1516, o título é muito maior): a descrição de Amaurotum, capital da república insular de Utopos, construída sobre uma vertente pouco declivosa da margem do rio Anydrus. Uma cidade muralhada, com fossos profundos e largos cheios de sebes e silvados, de planta quadrangular, com ruas largas convenientemente dispostas e orientadas, ladeadas por correntezas de casas de três andares, belas e bem construídas, de paredes reforçadas com vigas de madeira e revestidas, no exterior, de pedra, gesso ou tijolo, em cujas traseiras havia vastos jardins e pomares tratados com muita habilidade e grandes cuidados. As janelas tinham vidros ou painéis de tecido de linho muito fino embebido em azeite ou âmbar, de modo a deixar entrar a luz. Mas nem sempre fora assim. A cidade, milenária, começara como uma povoação de cabanas construídas com bocados de madeira, paredes de lama amassada e telhados de colmo.

Também neste caso a descrição clara e atraente de Amaurotum, complementada com a forma da sua administração, conduz o leitor à construção mental de uma imagem ou "paisagem» da cidade. Só que a descrição resultou da imaginação fértil de Thomas More, no acto de criação literária de um modelo de reino de paz e justiça social e económica (situado em nenhures, a utopia), em oposição aos de desordem e injustiça que imperavam na Europa (a realidade), de que a Inglaterra de quinhentos era um exemplo. Recordemos que Utopia é uma obra de crítica arrasadora e consciente da situação social e económica deste país (livro primeiro), que o autor pode fazer com base em conhecimentos directos, dada a sua posição social e cargos de responsabilidade desempenhados, e o projecto de propostas para a construção de uma sociedade mais equitativa e equilibrada (livro segundo). No humor non sense que permeia os dois livros, tão do gosto de Thomas More, contam muito as palavras por ele forjadas 
propositadamente. Assim, por exemplo, foi buscar Amaurotum a amauros (esfumado, nevoento, baço), o adjectivo que Homero aplicou à visão esfumada que, num sonho, Penélope teve de Atenas (Odisseia, IV, 824, 835); a tradução poderá ser «castelo no ar» ou "cidade de sonho». Anydros vem de $a$ (sem) e hudor(água), logo, o absurdo de «rio sem água».

\section{FORMAS DIFERENTES DE VER OU SENTIR A REALIDADE}

A noção de «paisagem» aparece na Europa com os tempos modernos, ligada, intimamente, às transformações que, do século XV ao XVII, produziram a perspectiva dita clássica (recuperação da plástica helenística), em substituição da perspectiva monocular, o método experimental de Francis Bacon, com uma nova concepção da maneira de interrogar a natureza, o dualismo de Descartes, a geometria das projecções, o desenvolvimento da cartografia, etc. Em resumo, a abstracção do sujeito fora do seu meio, a qual reduziu este, progressivamente, a uma coisa objectivável e manipulável. Na Ásia Oriental, por exemplo, no Japão, a noção de shanshui - ao mesmo tempo os montes e as águas e o quadro que os representa - é muito mais antiga e implica uma fusão cósmica do homem e do universo.

A "paisagem» tem linhas e planos, tem luzes e cores. Neste sentido, recordo as obras de pintores paisagistas dos séculos XVII e XIX, no primeiro caso os holandeses Pieter Claesz e Willem Kalff, Jacob Van Ruysdael e Meindert Hobbema, e no segundo os impressionistas Claude Monet, Camille Pissarro, Alfred Sisley, Georges Seurat, Paul Cézanne, e tantos outros. Estes, até serem chamados «impressionistas», viam-se como «realistas», de realismo relacionado com as suas maneiras de ver o mundo, de modo não clássico, não literário.

Sendo demasiado longo referir de cada um o mais importante acerca de "paisagem», fico por dois dos primeiros e pelos dois últimos dos segundos. As paisagens de Van Ruysdael e do seu discípulo Hobbema não se limitam a reproduzir particularidades topográficas. Exprimem também o carácter mudável da natureza: as nuvens ondeam, rastos de sombras deslizam sobre os campos, uma vegetação vigorosa revela o interesse do estilo barroco pelo crescimento e o movimento. De Claude Monet refiro, sobretudo, o quadro As papoilas, pintado em Argenteuil, em 1873, no qual convergem diversos elementos. Por um lado, se atendermos à sua composição, o conhecimento que o autor tinha da estampa japonesa, da qual toma o gosto pelo grande primeiro plano de paisagem vegetal; por outro lado, do ponto de vista da técnica, a definitiva vontade de captar impressões momentâneas. O quadro corresponde ao propósito de perceber a aparência cambiante da paisagem, o que exige uma execução rápida e, naturalmente, a observação directa. Da instantaneidade do momento dão fé as quatro figuras humanas, simplesmente delineadas, que transitam pelo lugar.

Quanto aos dois últimos, nas suas técnicas de execução encontram-se muitas afinidades com os processos de observação e registo gráfico praticados 
em Geografia. De Georges Seurat, o mais velho dos dois, pintor de paisagens fluviais e marinhas, sublinho a sua investigação dos problemas cromáticos ou do contraste simultâneo das cores e do valor das linhas construtivas. Quanto ao cromatismo, substituiu os efeitos de luz-cor, que os impressionistas obtinham com pinceladas justapostas, por uma síntese de touches divisées, isto é, dos tons complementares que se efectuaria na retina do observador, criando assim uma técnica que outros viriam a definir como pointillisme (pontilhismo ou divisionismo).

As paisagens de Paul Cézanne são de um grande rigor arquitectónico. Para a sua elaboração costumava sentar-se perante o que via, estudava cuidadosamente o "motivo» antes de o trasladar para a tela; atendia aos valores plásticos e escalonava os planos sucessivos, cuja situação exacta sublinhava por matizes de um colorido de tons finos, aplicado mediante séries apertadamente unidas de pinceladas paralelas, verticais ou oblíquas, à maneira dos sombreados de um esboço a lápis. As árvores, as casas os postes, as chaminés, constituíam outros tantos acentos rítmicos, que era preciso subordinar à unidade do quadro. Olhando a realidade, era fácil ver que, podendo apontar-se algumas liberdades do pintor, os aspectos naturais essenciais estão registados em qualquer das suas paisagens, recriados, magistralmente, com pinceladas ou toques de tinta como elementos de construção emotiva. Há quem aproxime o espaço de Cézanne daquele do shanshui. $\mathrm{O}$ estudo das suas paisagens constitui um bom exercício de análise fractal.

Outra linguagem universal para exprimir a "paisagem»é a da música, que recordo com o exemplo da Sinfonia n. ${ }^{\circ}$ 6, Pastoral, de L. Van Beethoven, cujo tema fundamental é o da reconciliação do homem com a natureza. Escrita em 1806-1808, foi publicada no ano seguinte com o título de «Sinfonia Pastoral, ou recordação da vida campestre (mais expressão de uma sensação do que pintura)» e numa nota o autor escreveu que «exprime-se nela, com cambiantes peculiares, as impressões que o campo pode suscitar no homem». Ao $1 .^{\circ}$ andamento chamou «despertar de sentimentos de alegria ao chegar ao campo», ao $2 .^{\circ}$ "cena à beira de um regato" (quanto maior o regato, mais profundo o tom), ao $3 .^{\circ}$ "alegre reunião de camponeses», ao $4 .^{\circ}$ "trovoada; tempestade», e ao 5..$^{\circ}$ "canto dos pastores, sentimentos de contentamento e gratidão após a tempestade». É impossível ouvir Nas estepes da Ásia Central de Borodine, ou Contos dos Bosques de Viena de J. Strauss, ou Pinheiros de Roma de Respighi sem fazer desfilar mentalmente as paisagens sugeridas por essas músicas.

\section{DA FICÇÃO À REALIDADE}

Vários autores de todos os tempos ficcionaram visões da Terra a partir de pontos de observação no espaço, nomeadamente do seu satélite Lua. Há cerca de cem anos um cientista importante como E. Suess escreveu o seguinte: «Se um observador no espaço celeste pudesse, ao aproximar-se do nosso 
planeta, afastar os mantos de nuvens de um castanho avermelhado que obscurecem a atmosfera e contemplar a superfície do globo, tal como ela se lhe apresentaria no decorrer de uma rotação...». Não adivinhava o autor da frase quanto isso mesmo e muito mais viria a suceder e a generalizar-se pouco mais de cinquenta anos depois.

A conquista do espaço exterior foi inaugurada em Outubro de 1957, com o lançamento do primeiro Sputnik, apenas com instrumentos diversos de medição de características físicas da atmosfera. Quase seis anos depois, em Abril de 1961, Yuri Gagarin foi o primeiro homem no espaço ainda desconhecido, abrindo-se assim o caminho para outras experiências, que tiveram como momento culminante a primeira descida do homem na Lua. A 21 de Julho de 1969 o astronauta Neil Armstrong podia dizer a frase que marcou o memorável evento: «That's one small step for a man, one giant leap for humanity».

Pela primeira vez o homem via o seu planeta e a atmosfera envolvente a partir de vários pontos da esfera celeste. As fotografias (orbitais) a cores feitas pelos astronautas das missões Gemini de 1965 e 1966 introduziram novos argumentos para as discussões em torno do conceito de "paisagem». Mais impressionantes, porém, foram as séries de imagens fornecidas desde 1972 pelos sensores dos satélites Ersts/Landsat, registando não só valores de energia emanada pelos corpos da superfície terrestre (terras e águas, formas de relevo e estruturas geológicas, coberturas pedológicas e vegetais, áreas desérticas, quer geladas, quer arenosas e rochosas, campos cultivados, grandes aglomerações urbanas, etc.), em diversos comprimentos de onda (domínios espectrais do ultra-violeta ao UHF), mas também aspectos de uma determinada área da superfície do globo em vários momentos ou tempos.

Mostraram assim que às três dimensões tradicionais de qualquer fenómeno geográfico tinha de se juntar uma quarta: a energética. E com esta foi a própria noção de espaço que se modificou. Evidenciaram, o que já se sabia, mas agora de forma mais expressiva e quantificável, as modificações das "paisagens» no decorrer do tempo. Não há realidades fixadas eternamente. Permitiram que, pela primeira vez, tivéssemos meios para monitorizar e avaliar as nossas interacções com a natureza em todas as suas inumeráveis ramificações.

Hoje o mundo todo é a nossa unidade de pensamento e acção. Nada pode desenvolver-se em isolamento: as alterações numa «paisagem» produzem reacções nas outras vizinhas. Esta nova consciência de mudança da realidade é, porventura, um dos maiores triunfos da conquista do espaço.

Em tempos de caminhada veloz da construção da sociedade dita da informação, vista esta e a comunicação como factores essenciais de mudança, como o sistema nervoso das sociedades contemporâneas, lembro, sem juntar quaisquer comentários, os conceitos que se formulam de ciberespaço e de cibertempo, há muito passados da ficção científica para a investigação científica e sua aplicação. 